\title{
Uterine mast cell tumor: a clinical and cytohistopathological study
}

\author{
Ali Mohammad Bahrami ${ }^{1}$, Fariba Khaki ${ }^{2}$, Shahram Zehtabian ${ }^{3}$, Javad Cheraghi ${ }^{4 *}$, Mehdi Rashnavadi ${ }^{1}$ \\ Mohammad Reza Hafezi Ahmadi ${ }^{5}$, Mostafa Naderafif ${ }^{6}$, Soheil Javaherypour ${ }^{7}$, Siamak Mohsenzadeh ${ }^{6}$ \\ Ehsan Hosseini ${ }^{4}$, Hamed Masoudi ${ }^{7}$ and Mehdi Pourzaer ${ }^{2}$
}

\section{Abstract}

Background: Mast cells are one of the characteristic factors in angiogenesis, growth, and metastatic spread of tumors. Further studies are suggested to determine the type of these cells which might be elseful in the assessment of biological nature of the tumor and its future treatment modality. Few studies have evaluated mast cell infiltration in visceral tumors, especially uterine tumors.

Case presentation: In this study, age, sex, death rate, and histologic,patterns were in agreement with those of previous reports on canine mast cell tumors. Cytopathology assays are widely used to prognosticate canine uterine mast cell tumors (MCT). There is limited information about these prognostic assays used on MCT that arise in the uterine. The anisocytosis and anisocytosis and giant cells were present in the tumor. Furthermore, the tumor had nuclear atypia with scattered multinucleated cells and prominent hucleoli and tumor were classified as poorly granulated. Under microscopic examination, we observed diffuse infiltration and proliferation of tumor cells from the uterine different area and the infiltrative characteristics and distribution patterns of neoplastic cells were observed. This tumor consisted of sheets and cords of uniforna round cells with discrete cytoplasmic margins. Microscopically, the neoplastic masses were poorly-demarcated and lacked capsules and tumor cell usually showed a distinct cell boundary. Nevertheless, the neoplastic cells were located between collagen bundles forming small clusters and sheets and had large, centrally located, round to ovoid nuclei. In addition, eosinophils were scattered among the mast cells at the periphery of the masses. The presence of eosinophils and the observation, at high magnification, of cells with cytoplasmic metadhromatic granules.

Conclusion: Based on these findings, a diagnosis of poorly-differentiated mast cell tumor was made and data histologic grading was available for tumor. Neoplasm was poorly differentiated or gradelll.

Keywords: Mact cell tumor, Histopathology, Cytology, Uterine, Diagnosis

\section{Background}

Epithelial uterine neoplasia is the most lethal gynaecological malignancy in the today world and advanced disease remains incurable for the majority of patients. Recent insights have indicated that uterine cancer is a collective term for invasive pelvic cancers that are derived from multifarious tissues with distinct histological and epidemiological features [1-3].

\footnotetext{
* Correspondence: j.cheraghi@mail.ilam.ac.ir

${ }^{4}$ Department of Physiology, Faculty of Para Veterinary Medicine, Ilam University, llam, Iran

Full list of author information is available at the end of the article
}

Several histopathologic categories have been recommended to identify the degree of differentiation of canine mast cell tumors (MCTs). Among them, the classification proposed by Patnaik et al. is considered to be the most complete and is the one most frequently utilized. Nevertheless, histopathologic grading is based on the use of subjective parameters such as invasiveness, mitotic index, cellularity and cellular morphology (pleomorphism of tumor cells), and often proves to be inconsistent for the evaluation of borderline cases. Although histopathologic grading is considered to be a well approach for the prediction of long-term cancer behavior, 
reproducibility problems lead to as much as $50-60 \%$ discordance between experienced pathologists [2,4-7].

MCTs are among the most frequent types of dog neoplasms, representing approximately $20 \%$ of the skin tumors and it is a usual tumor in felines and may represent up to $20 \%$ of all cutaneous tumors. 5 Sexual predisposition has not been reported, and etiology has not been identified. MCTs account for $2-15 \%$ of all tumors in pets, and are classified anatomically into cutaneous and visceral forms $[8,9]$. The cutaneous form of MCTs predominates in pets, with MCTs being the second most common skin tumor in these animals. Cutaneous MCTs are most often located on the head, neck and trunk and are divided histologically into two forms: mastocytic and atypical (previously histiocytic). The mastocytic form of the disease is the more common of the two, and is further sub-classified into well-differentiated (previously compact) or poorly differentiated (previously pleomorphic or diffuse) forms [10-13].

Mastocytic well-differentiated (compact) tumors are circumscribed, non-encapsulated masses that consist of solid sheets of uniform round cells with little mitotic activity. These are the most common histological type, accounting for $60 \%$ of feline cutaneous MCTs in one review. Mastocytic poorly differentiated (pleomorphic) MCTs are less common, accounting for $<28 \%$ of all $\mathrm{fe}-$ line cutaneous MCTs. They are characterized by pleomorphism, mononuclear or multinucleated giant cells and infiltrate the dermis and subcutis. This variant commonly contains eosinophils. The majority have a yery low mitotic rate ( $<1$ mitosis per 10 high power fields). The mitotic rate appears to be prognostic in this subset of feline cutaneous MCTs, as those cats with poorly differentiated tumors with a high mitotic rate have a more behaviorally malignant disease [12,14-16].

Visceral MCTs most often affect the spleen, accounting for $15-26 \%$ of splenic disease in pets $[17,18]$. The alimentary tract is another common location for visceral tumors, with MCTs being the third most common form of pet intestinal neoplasia. Visceral MCTs may be associated with secondary cutaneous lesions. Other reported non-cutaneous MCT sites include the liver, lymph nodes and nasal cavity $18-20]$.

Because of the high outbreak of MCTs, their variable biological behavior, the potential fatal outcome attributed to aggressive disease or paraneoplastic syndromes, and the costs and risks associated with treatment, accurate prognostication of MCTs is critical [21-25]. Cytopathologic examination is a low-cost, rapid, and simple method for the diagnosis of cutaneous neoplasms $[6,8]$. However, there are no objective criteria for the cytologic grading of MCTs alone regarding malignancy, which forces clinicians and surgeons to submit tissue fragments for histopathologic analysis and subsequent grading. The aim of this report was to the evaluation of the uterine MCT with cytology and histopathology methods for the first time in a visceral organ with an accurate diagnosis

\section{Case presentation}

\section{Animal ethics}

The animal was placed in shade, in standard conditions, water ad libitum, and without restriction of movement according to the guidelines of Institutional Animal Ethical Committee of the Animal Science, Tran. Surgery was performed under aseptic conditions and sedation by injection of Xylazine hydrochloride $(0.05 \mathrm{mg} / \mathrm{kg})$ followed by $2 \%$ Lignocaine hydrochloride.

In August 2014, a 4-year-old, 6 kg, female black terrier that was presented to a rivate clinic for evaluation of a 3- $3.7 \mathrm{~cm}$-diameter, red to white, firm nodules with adherent crusts and had a sunken appearance at the right dorsolateral aspect of the uterine. The largest mass measured $3.7 \mathrm{~cm}$ in diameter, while the smaller mass was $3.0 \mathrm{~cm}$ in diameter. Neither ulceration nor hemorrhage was observed. The mass was surgically resected and an impression snear of the tissue was prepared and stained with Giemsa. The rest of the tissue was subjected to histopathologic evaluation. The cytopathology smear was prepared and one of the smears was air dried and stained with hematoxylin and eosin (HE). Fine needle aspirates of the uterus was aspirated and interpreted at the clinic as containing numerous, poorly-differentiated mast cells. Complete blood cell count and serum biochemical profiles were not performed; thoracic radiographs and abdominal ultrasound were normal. An incisional biopsy specimen was submitted for histopathologic examination.

At autopsy, all uterine sample was initially fixed in buffered formalin (not exceeding $4 \%$ formaldehyde) prior to embedding in paraffin. The neoplasm was fixed in $10 \%$ formaldehyde and routinely processed for histopathology. Two 5- $\mu \mathrm{m}$ sections were obtained from each tumor, stained with $H \& E$, and submitted to two experienced pathologist for histopathologic grading according to previously published guidelines. The final diagnosis was established by consensus of 2 or more observers.

Tumor was classified independently by two pathologists in order to confirm the diagnosis according to the WHO criteria [16]. Also tumor was graded according to the criteria proposed by Patnaik et al. [5] and Kiupel et al. [26], as well, moderately or poorly differentiated (grades I, II or III, respectively) $[5,26]$. These criteria included the following histomorphological features: extent of tumor (invasiveness), cellular morphology, size of cytoplasmic granules, mitotic activity and stromal reaction. Invasiveness was assessed as follows: non-invasive (tumors confined to the superficial dermis and interfollicular spaces); moderately invasive (tumors with lower dermal and limited subcutaneous tissue invasion); highly 
invasive (tumors with massive infiltration of subcutaneous and deep tissue). Mitotic activity was assessed on toluidine blue-stained sections, five high power fields (hpfs) being evaluated in each case with $a \times 40$ objective. The data were expressed as mean number of mitoses per hpf (mitotic index) and tumors were classified according to the following grading system: 0 (mitotic figures absent); 1 (mitotic index ranging from 0 to 2 mitoses/hpf); 2 (mitotic index > $2 / \mathrm{hpf}$ ). Invasiveness and mitotic activity assessment were used to define the histological grade, and also as individually evaluated parameters.

Criteria for inclusion in the present study included the availability of cytopathologic and histopathologic samples for morphometric analysis, confirmation of the MCT diagnosis

\section{Cytology and histopathology findings}

The anisocytosis and anisocytosis and giant cells were present in the tumor. Furthermore, the tumor had nuclear atypia with scattered multinucleated cells and prominent nucleoli and tumor were classified as poorly granulated. They comprised solid sheets of large polygonal to round-shaped cells with large vesicular nuclei, occasionally slightly indented and also, pleomorphic cells had significantly higher (Figure 1).

The histologic features on HE-stained sections included the following:
Under microscopic examination, we observed diffuse infiltration and proliferation of tumor cells from the uterine different area and the infiltrative characteristics and distribution patterns of neoplastic cells were observed (Figure 2). This tumor consisted of sheets and cords of uniform round cells with discrete cytoplasmic margins. Microscopically, the neoplastic masses were poorly-demarcated and lacked capsules and tumor cell usually showed a distinct cell boundary (Figures 3 and 4). Nevertheless, the neoplastic cells were located between collagen bundles forming small clusters and sheets and had large, centrally located, round to ovoid nuclei. In the some cells, the nuclei had scattered or dense chromatin with small distinct nucleoli and the nuclei had reticulated with two or three small nucleoli visible. High powered fields contained the high mitotic figures (Figures 3 and 4). The neoplastic cells had moderate amounts of finely granular cytoplasm and distinct cellular boundaries. Moreover, thin or thick fibrous stroma was observed in the some of tumor. Changes in blood vessels and presence and distribution of eosinophils and other inflammatory cells were seen. Eosinophil infiltration was present in tumor and lymphoplasmacytic infiltration of the uterine parenchyma was sharply demarcated (Figure 5). Poorly MCTs had numerous eosinophils, significantly more than in pleomorphic MCTs. Based on these findings, a diagnosis of poorly-differentiated mast cell tumor was

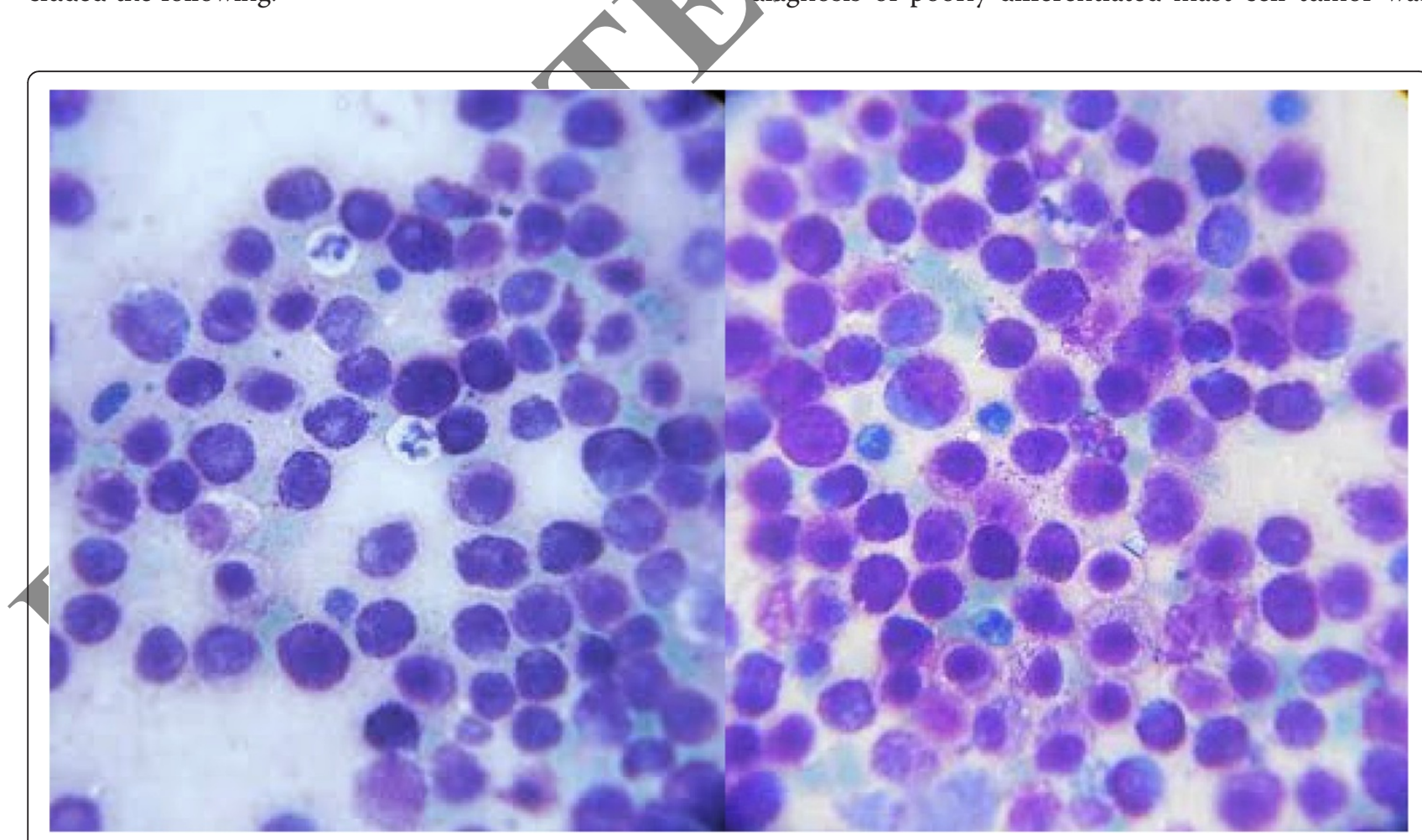

Figure 1 Fine-needle aspirate smear of a mast cell tumor, uterus; dog. There are many large round cells with centrally placed round nuclei, Mastocytic pleomorphic types: Moderate to marked pleomorphism and abundant infiltrate of small lymphocytes and at high magnification, nuclei are large and eccentric and have variable chromatin patterns, and nucleoli are generally prominent. H\&E. 


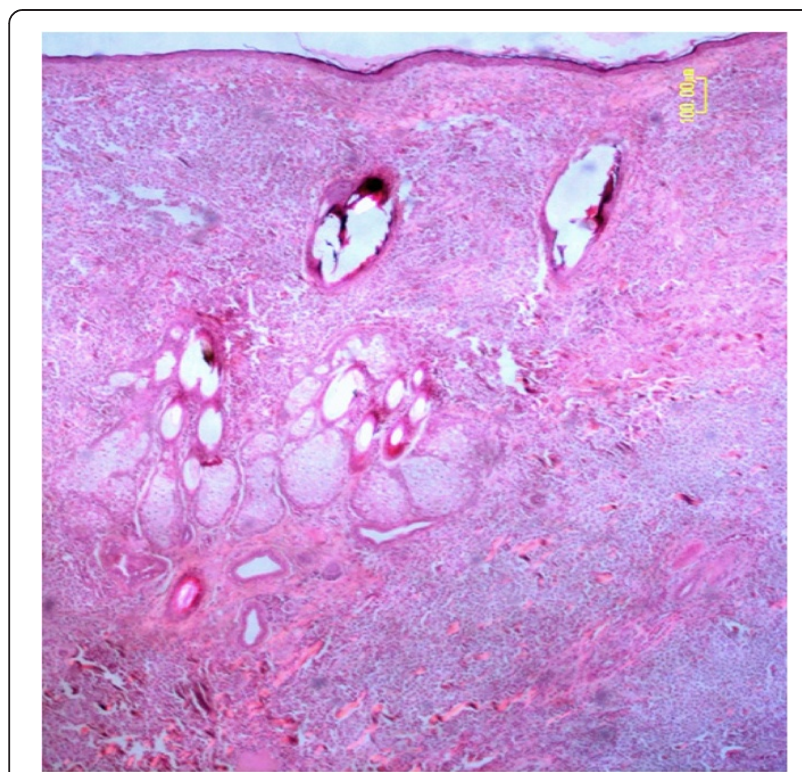

Figure 2 Histopathology of a tumoral mass from the uterine of the dog. Neoplastic mast cells form dense sheets within the intraparenchymal uterus. Hematoxylin and eosin stain, $\times 200$. Bar $=100 \mu \mathrm{m}$.

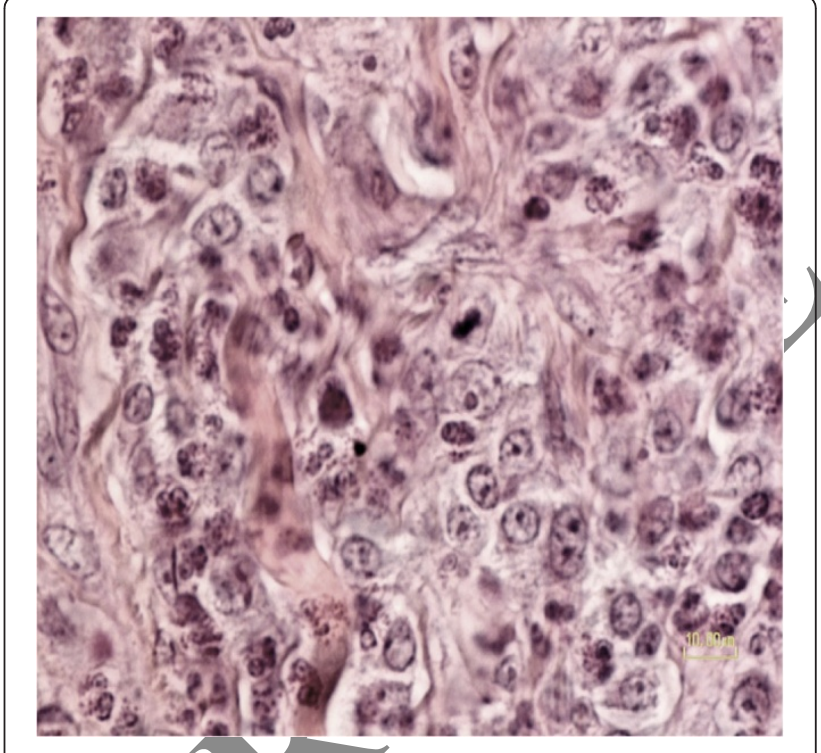

Figure 4 Photomicrograph of a poor-circumscribed canine

uterus mast cell tumor. Mitotic index is recorded as the number of mitotic figures. Neoplastic mast cells are arranged as single cells, loose aggregates, and rows linearly arranged along collagen fibers, as supported by abundant collagenous stroma interspersed with eosinophils Hematoxylin and eosin, $\times 400$. Bar $=10 \mu \mathrm{m}$. made and data histologic grading was available for tumor. Neoplasm was poorly differentiated or grade 11 .

\section{Discussion}

Mast cell tumors (MCTs) are common in many animal species. Within the cutaneous, the tumon can be focal or

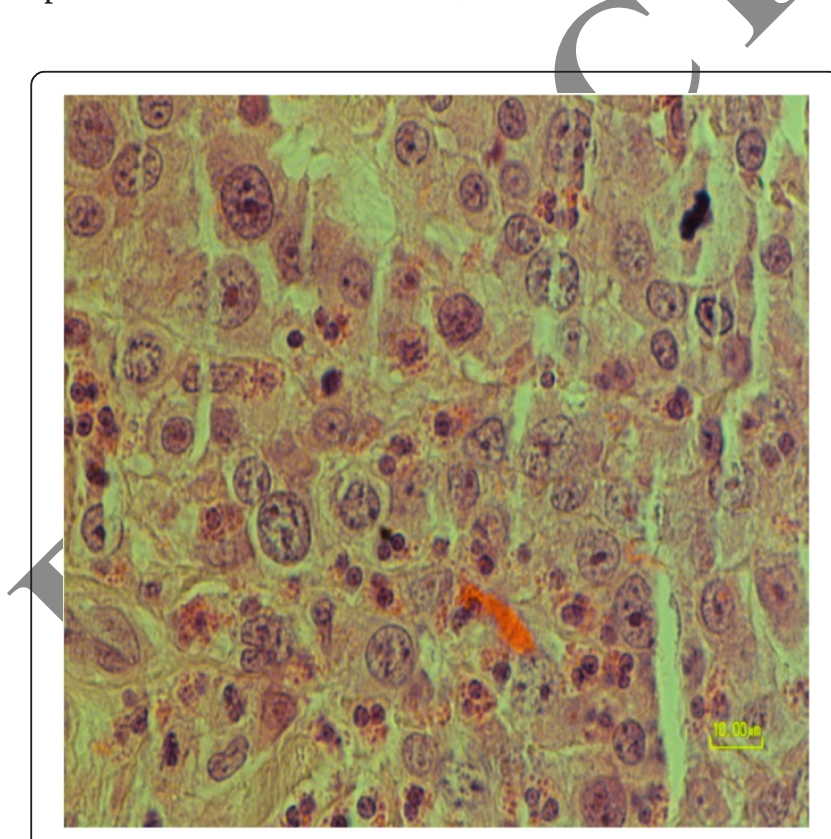

Figure 3 Uterine mast cell tumor, dog. Pleomorphic, round to spindle cells containing a variably sized nucleus are observed. Infiltration of eosinophils is prominent together with mitotic figures. Hematoxylin and eosin, $\times 400$. Bar $=10 \mu \mathrm{m}$. multicentric and may occasionally involve internal viscera such as the spleen, the liver, or the intestine [4]. Furthermore, in canine, MCTs most commonly occur as skin masses and tend to metastasize to local lymph nodes and internal organs, such as spleen and liver [27].

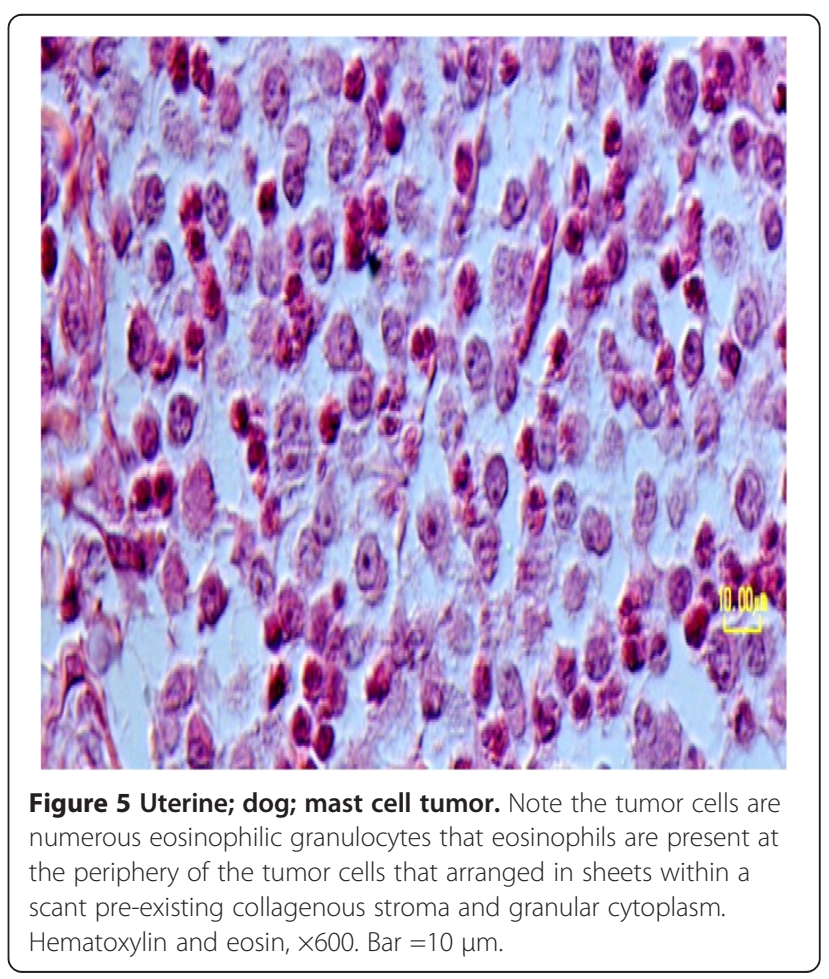


The mean age and the breed of dog represented in this study was similar to those in previous reports on canine MCT [2,7,9-11,28]. The predominance of females with mast cell tumors, although not statistically significant, agrees with findings in one report [29]. Other researchers have indicated no sex difference in the incidence of these tumors $[5,28,30]$. The distribution of mast cell tumors and incidence of metastasis were similar to previous finding $[5,31]$. However, one report showed a higher percentage of dogs with met astatic mast cell tumors, possibly reflecting a different duration of the disease.I5. In our study the incidence of canine mast cell tumor is similar to other species [32,33]. Our morphologic findings, tumor distribution, and age at diagnosis were similar to previous reports [32,34,35].

Several grading systems have been proposed to classify canine mast cell tumors. The system most commonly used classifies the tumor from grades I to III, depending on how well the mast cells are differentiated, mitotic activity, location within the skin, invasiveness, and the presence of inflammation or necrosis, with grade III being the most aggressive (characterized by the presence of undifferentiated, immature mast cells with a high potential for metastasis) [5]. In the current case, the presence of multiple large nodules/or masses, the extension into the uterine multifarious area, and the poorly differentiated mast cells could be comparable to grade AII described for dog.

Furthermore, intratumoural microvessel density has been evaluated in canine MCT and has been associated with tumor recurrence and mortality [36]. In the present study, an increase of mast cell infiltration and microvessel density with grade III was observed in MCT sample by histopathology. On the other hand, the results of this study suggest that cellular proliferation plays a significant role in the progression of canine MCTs. Although the results of this study confirm the results of previous studies that have shown the prognostic significance of cellular proliferation in canine MCTs [37-39] cellular proliferation should not be evaluated as a single prognostic factor for canine MCTs but should be evaluated in tandem with additional prognostic indicators. Furthermore, the histologic characteristics of the MCT cells in this affected dog was moderate to abundant cytoplasm, round nuclei with scattered chromatin, fibrous stroma, and eosinophil infiltration. Little necrosis was seen.

On the other hand, a subset of tumors termed poorly differentiated have exhibited aggressive biologic behavior $[15,40]$. Those tumors were described as meeting criteria of malignancy, including anisokaryosis, anisocytosis, nuclear pleomorphism, high mitotic rate, and uninucleated and multinucleated giant cells. In our study, the tumor from dog exhibited all these characteristics, including high mitotic rate, and this dog experienced tumor spread. The outcome in this cat supports the conclusions of previous researchers that tumors meeting cytomorphologic criteria of malignancy with high mitotic activity are behaviorally aggressive. These findings suggests cellular pleomorphism and mitotic index alone are indicative of aggressive behavior of uterine MCT

Cytopathology often is helpful in the diagnosis of MCTs because of the characteristic appearance of mast cells with routine staining. As is the case with findings from other species, Wright-Giemsa stain resulted in more intensely stained granules in the neoplastic mast cells

\section{Conclusion}

In the present study, highly cellular tumor presented extremely anaplastic cells with few granules that invaded adjacent tissue, where areas of necrosis were also observed. This tumor was classified as grade III and also, the large majority of uterine MCT with cytomorphologic features such as anisocytosis, anisokaryosis, nuclear atypia, and multiple muclei had benign biologic behavior. High mitotic rate and cellular pleomorphism were as an indicator of aggressive behavior. This is the first reported case of uterine mast cell tumor in a dog supported by cytology, and histopathology. After completely excising the tumor, no further treatments were attempted, and no recurrence has been noted to date.

\section{Consent}

Written informed consent was obtained from the owner of the patient for the publication of this case presentation and any accompanying images. A copy of the written consent is available for review by the Editor-in-Chief of this journal.

\section{Abbreviations \\ MCT: Mast cell tumors; HE: Hematoxylin and eosin.}

\section{Competing interests}

The authors declare that they have no competing interests.

\section{Authors' contributions}

AMB, FK and MRHA collected clinical and pathological data and drafted the manuscript and participated the histopathological evaluation, performed the literature review, acquired photomicrographs and drafted the manuscript and gave the final histopathological diagnosis. JCH performed sequencing alignment and manuscript writing. SHZ, EH and MP helped with manuscript drafts and edited for language and grammar. MR, MN, SJ, SM and HM edited the manuscript and made required changes. All authors participated in the preparation of the manuscript as well as reviewed and approved the final manuscript.

\section{Acknowledgements}

The authors thank Dr. Javad Javanbakht, Faculty of Veterinary Medicine, Tehran University, Iran, for help with this manuscript.

\section{Author details}

${ }^{1}$ Faculty of Para Veterinary Medicine, Ilam University, Ilam, Iran. ${ }^{2}$ Department of Pathology, Faculty of Veterinary Medicine, Tehran University, Tehran, Iran. ${ }^{3}$ Department of Microbiology, Faculty of Medicine, Kermanshah University of 
Medical Sciences, Kermanshah, Iran. ${ }^{4}$ Department of Physiology, Faculty of Para Veterinary Medicine, Ilam University, Ilam, Iran. ${ }^{5}$ Department of Pathology, Faculty of Medicine, Ilam University of Medical Sciences, Ilam, Iran. ${ }^{6}$ Department of Pathobiology, Faculty of Veterinary Medicine, Ferdowsi University of Mashhad, Mashhad, Iran. ${ }^{7}$ Student of Veterinary Medicine, Faculty of Veterinary Medicine, Urmia University, Urmia, Iran.

Received: 17 August 2014 Accepted: 27 October 2014

Published online: 07 November 2014

\section{References}

1. Miller RL, Van Lelyveld S, Warland J, Dobson JM, Foale RD: A retrospective review of treatment and response of high-risk mast cell tumours in dogs. Vet Comp Oncol 2014 Sep 15. doi:10.1111/vco.12116. [Epub ahead of print]

2. Hosseini E, Pedram B, Bahrami AM, Moghaddam MH, Javanbakht J, Ghom FE, Moghaddam NJ, Koohestani M, Shafiee R: Cutaneous mast cell tumor (Mastocytoma): cyto- histopathological and haematological investigations. Diagn Pathol 2014, 9:9.

3. Jiang $L$, Hua $Y$, Shen $Q$, Ding $S$, Jiang $W$, Zhang $W$, Zhu X: Role of mast cells in gynecological neoplasms. Front Biosci (Landmark Ed) 2013, 18:773-781.

4. Goldschmidt MH, Hendrick MJ: Tumors of the skin and soft tissues. In Tumors in Domestic Animals. 4th edition. Edited by Meuten DJ. Ames, lowa: lowa State Press; Blackwell. Publishing Company; 2002:64-67.

5. Patnaik AK, Ehler WY, MacEwen EG: Canine cutaneous mast cell tumors: morphologic grading and survival time in 83 dogs. Vet Pathol 1984, 21:469-474.

6. Shafiee R, Javanbakht J, Atyabi N, Kheradmand P, Kheradmand D, Bahrami A, Daraei H, Khadivar F: Diagnosis, classification and grading of canine mammary tumours as a model to study human breast cancer: an Clinico-Cytohistopathological study with environmental factors influencing public health and medicine. Cancer Cell Int 2013, 13(1):79.

7. Donnelly L, Mullin C, Balko J, Goldschmidt M, Krick E, Hume C, Brown DC, Sorenmo K: Evaluation of histological grade and histologically tumour-free margins as predictors of local recurrence in completely excised canine mast cell tumours. Vet Comp Oncol 2013 Mar 4. doi:10.1111/vco.12021. [Epub ahead of print]

8. Shafiee R, Javanbakht J, Atyabi N, Bahrami A, Kheradmand D, Safaei R, Khadivar F, Hosseini E: Comparative value of clinical, cytological, and histopathological features in feline mammary gland tumors; an experimental model for the study of human breast cancer. Diagn Pathol 2013, 8:136

9. Brønden $L B$, Eriksen T, Kristensen AT: Mast cell tumours and other skin neoplasia in Danish dogs-data from the Danish Veterinary Cancer Registry. Acta Vet Scand 2010, 52:6.

10. Oliveira FN, Elliott JW, Lewis BC, Mathews GG, Brown RM, Treadway CM, Langohr IM: Cutaneous mast cell tumor with epitheliotropism in 3 dogs. Vet Pathol 2013, 50(2):234

11. Schlieben P, Meyer A, Weise C, Bondzio A, Einspanier R, Gruber AD, Klopfleisch R: Differences in the proteome of high-grade versus lowgrade canine cutaneous mast cell tumours. Vet J 2012, 194(2):210-214.

12. Henry C, Herrera C: Mast cell tumors in cats: clinical update and possible new treatment avenues. Feline Med Surg 2013, 15(1):41-47.

13. Skeldon NCA, Gerber KL, Wilfon RJ, Cunnington SJ: Mastocytaemia in cats: prevalence, detection and quantification methods, haematological associations and potential implications in 30 cats with mast cell tumours. F Fel Med and Surg 2010, 12(12):960-966. Govier SM: Principles of treatment for mast cell tumors. Clin Tech Small Anim Pract 2003, 18(2):103-106. Wilcock BP, Yager JA, Zink MC: The morphology and behaviour of feline cutaneous mastocytomas. Vet Pathol 1986, 23(3):320-324.

16. Jolninson TO, Schulman FY, Lipscomb TP, Yantis LD: Histopathology and biologic behaviour of pleomorphic cutaneous mast cell tumours in fifteen cats. Vet Pathol 2002, 39(4):452-457.

17. Litster AL, Sorenmo KU: Characterisation of the signalment, clinical and survival characteristics of 41 cats with mast cell neoplasia. J Fel Med and Surg 2006, 8(3):177-183.

18. Spangler WL, Culbertson MR: Prevalence and type of splenic diseases in cats: 455 cases (1985-1991). J Am Vet Med Assoc 1992, 201:773-776.

19. Madewell B, Theilen GH: Mast cell and melanocytic neoplasms. In Veterinary Cancer Medicine. 2nd edition. Edited by Theilen Gand Madewell B. Philadelphia: Lea \& Febiger; 1987:310-315.
20. Rissetto K, Villamil JA, Selting KA, Tyler J, Henry CJ: Recent trends in feline intestinal neoplasia: an epidemiologic study of 1129 cases in the veterinary medical database from 1964 to 2004. J Am Anim Hosp Assoc 2011, 47:28-36.

21. McEntee MF: Equine cutaneous mastocytoma: morphology, biological behaviour and evolution of the lesion. J Comp Pathol 1991, 104(2):171-178.

22. Blackwood L, Murphy S, Buracco P, De Vos JP, De Fornel-Thibaud P, Hirschberger J, Kessler M, Pastor J, Ponce F, Savary-Bataille K, Argyle DJ: European consensus document on mast cell tumours in dogs and cats. Vet Comp Oncol 2012 10(3):e1-e29.

23. Bostock DE: The prognosis following surgical removal of mastocytomas in dogs. J Small Anim Pract 1973, 14:27-41.

24. Preziosi R, Sarli G, Paltrinieri M: Multivariate surviva fanalysis of histologic parameters and clinical presentation in canine cutaneous mast cell tumours. Vet Res Commun 2007, 31:287-296

25. Webster JD, Yuzbasiyan-Gurkan V, Kaneene JB, Miller R, Resau JH, Kiupel M: The role of c-KIT in tumorigenesis: evaluation in canine cutaneous mast cell tumors. Neoplasia 2006, 28:104

26. Kiupel M, Webster JD, Bailey KL, Best S, Delay J, Detrisac CJ, Fitzgerald SD: Proposal of a 2-tier histologic grading system for canine cutaneous mast cell tumors to more accurately predict biological behavior. Vet Pathol 2011, 48:147-155.

27. London CA, Seguin B: Mast cell tumors in the dog. Vet Clin North Am Small Anim Pract 2003, 33:473-489.

28. Larsson B: Some aspects of canine mastocytoma. Nord Veterinar med 1957, 9:241

29. Mulligan RM: Neoplastic diseases of dogs. Mast cell sarcoma, lymphosarcoma, histiocytoma. Arch Patho 1948, 146:477-492.

30. Nielsen SW Cole GR: Canine mastocytoma. A report of one hundred cases. Am Vet Res 1958, 19:417-432.

Hottendorf GH, Nielsen SW: Pathologic survey of 300 extirpated canine mastocytomas. Zentralbl Veterinarmed Reihe A 1967, 14:272-281. Migak i G, Carey AM: Malignantm astocytoma in a cow. Am J Vct Res 1972, 33:253-256

33. Stannard AA, Pulley LT: Tumor soft the skin and soft tissue. In Tumors in Domestic Animals. 2nd edition. Edited by MOUlton JE. Berkeley and Los Angeles, CA: University of California Press; 1978:26-32.

34. Groth AH, Bailey WS, Walker DF: Bovine mastocytoma. J Am Vet Med Assoc $1960,137: 241-244$

35. McGavin MD, Leis TJ: Multiple cutaneous mastocytomas in a bull. Aust Vet J 1968, 44:20-22. 196.

36. Preziosi R, Sarli G, Paltrinieri M: Prognostic value of intratumoral vessel density in cutaneous mast cell tumors of the dog. $J$ Comp Pathol 2004 130(2-3):143-151.

37. Gross TL, Ihrke PJ, Walder EJ, Affolter VR: Epithelial Neoplasms and Other Tumors. Section 2, Part I. In Skin Diseases of the Dog and Cat: Clinical and Histopathologic Diagnosis. $2^{\text {nd }}$ ed. Blackwell Publishing, 2005: 641-654

38. Bronden $L B$, Eriksen T, Kristensen AT: Mast cell tumours and other skin neoplasia in Danish dogs-data from the Danish Veterinary Cancer Registry. Acta Vet Scand 2010, 22:52-56.

39. Noli C, Miolo A: The mast cell in wound healing. Vet Dermatol 2001, 12:303-313.

40. Yager JA, Wilcock BP: Color Atlas of Surgical Pathology of the Dog and Cat, Dermatopathology and Skin Tumors. London, UK: Mosby-Year Book; 1994:273-274. 280-281.

doi:10.1186/s13048-014-0105-3

Cite this article as: Bahrami et al:: Uterine mast cell tumor: a clinical and cytohistopathological study. Journal of Ovarian Research 2014 7:105. 